\title{
A Corticosteroid-Responsive Transcription Factor, Promyelocytic Leukemia Zinc Finger Protein, Mediates Protection of the Cochlea from Acoustic Trauma
}

\author{
Marcello Peppi, ${ }^{1,4}$ Sharon G. Kujawa, ${ }^{1,2,4}$ and William F. Sewell ${ }^{1,3,4}$ \\ ${ }^{1}$ Eaton Peabody Laboratory and ${ }^{2}$ Department of Audiology, Massachusetts Eye and Ear Infirmary, and ${ }^{3}$ Program in Neuroscience and ${ }^{4}$ Department of \\ Otology and Laryngology, Harvard Medical School, Boston, Massachusetts 02114
}

\begin{abstract}
Animals can be induced to resist cochlear damage associated with acoustic trauma by exposure to a variety of "conditioning" stimuli, including restraint stress, moderate level sound, heat stress, hypoxia, and corticosteroids. Here we identify in mice a corticosteroidresponsive transcription factor, PLZF (promyelocytic leukemia zinc finger protein), which mediates conditioned protection of the cochlea from acoustic trauma. PLZF mRNA levels in the cochlea are increased following conditioning stimuli, including restraint stress, dexamethasone administration, and moderate-to-high level acoustic stimulation. Heterozygous mutant $\left(\right.$ luxoid.Zbtb16 $\left.{ }^{\mathrm{LU}} / \mathrm{J}\right)$ mice deficient in PLZF have hearing and responses to acoustic trauma similar to their wild type littermates but are unable to generate conditioninginduced protection from acoustic trauma. PLZF immunoreactivity is present in the spiral ganglion, lateral wall of the cochlea, and organ of Corti, all targets for acoustic trauma. PLZF is also present in the brain and PLZF mRNA in brain is elevated following conditioning stimuli. The identification of a transcription factor that mediates conditioned protection from trauma provides a tool for understanding the protective action of corticosteroids, which are widely used in treating acute hearing loss, and has relevance to understanding the role of corticosteroids in trauma protection.
\end{abstract}

\section{Introduction}

Exposure to very loud sounds can produce permanent hearing loss by irreplaceably damaging the sensory cells (hair cells) and auditory neurons in the cochlea. It has been known for decades that the cochlea can be conditioned to resist damage by prior exposure to moderate-level sounds (Miller et al., 1963; Canlon et al., 1988). The amount of protection is remarkable: up to $30 \mathrm{~dB}$ of permanent hearing loss can be prevented. The mechanism by which this protection is created is not understood. Some insight into this enigmatic phenomenon has come from experiments indicating that protection can also be induced by stress, including heat stress (Yoshida et al., 1999) and restraint stress (Wang et al., 2002), presumably via a corticosteroid-dependent process (Tahera et al., 2006a,b).

Here we identify a corticosteroid-responsive transcription protein, PLZF (promyelocytic leukemia zinc finger protein), which is essential to mediate cochlear protection. PLZF is a transcription suppressor in the family of Kruppel-type zinc finger proteins and contains a conserved POZ protein-binding domain at its $\mathrm{N}$ terminus. PLZF expression is corticosteroid responsive (Fahnenstich et al., 2003; Wasim et al., 2010), is expressed in the

Received July 29, 2010; revised 0ct. 26, 2010; accepted Nov. 5, 2010.

This work was supported by grants from the National Institutes of Deafness and Other Communications Disorders (DC 767 to W.F.S. and DC 8577 to S.G.K.) and the Deafness Research Foundation (to M.P.).

Correspondence should be addressed to William F. Sewell, Eaton Peabody Laboratory, Department of Otolaryngology, Massachusetts Eye and Ear Infirmary, 243 Charles Street, Boston, MA 02114. E-mail: wfs@epl. meei.harvard.edu.

DOI:10.1523/JNEUROSCI.3955-10.2011

Copyright $\odot 2011$ the authors $\quad 0270-6474 / 11 / 310735-07 \$ 15.00 / 0$ inner ear (Nagy et al., 2005), and has been identified as an interaction partner with prestin (Nagy et al., 2005), a cochlear motor protein responsible for amplifying acoustic input to the cochlea (Zheng et al., 2000). Thus PLZF is a reasonable candidate to mediate conditioning-induced protection in the cochlea.

We demonstrate that PLZF mRNA is elevated in the mouse cochlea (and brain) following restraint stress. We show it is present in the spiral ganglion, organ of Corti, and stria vascularis, all targets for acoustic trauma. Importantly, mutant mice deficient in PLZF have hearing similar to their wild-type littermates, but are unable to generate conditioning-induced protection from acoustic trauma. Finally, corticosteroid (dexamethasone) given either before or after noise exposure can also induce PLZF expression and protection.

The identification of a transcription factor that mediates protection from trauma provides a tool for understanding the protective action of corticosteroids, which are widely used in treating acute hearing loss (Rauch et al., 2000). PLZF is widely expressed in brain and in other tissues, leading to the possibility that our findings may be generalizable to other forms of conditioned protection and may have relevance to understanding the role of corticosteroids in trauma protection in general.

\section{Materials and Methods}

Animals. We used C57/BL/6J (B6) and CBA/CaJ (CB) mice in this study. The luxoid (PLZF) mutation is in a B6 background, but B6 mice show early hearing loss (Li, 1992; Ohlemiller et al., 2000). Therefore we confined our work in B6 mice to 6-week-old animals, which have CB-like hearing and CB-like susceptibility to acoustic trauma. However, cochlear PLZF mRNA levels are at their developmental peak at 6 weeks of age and 
drop to much lower levels at 10-12 weeks (see Fig. $2 a$, below), a time when B6 mice are beginning to show some hearing loss. So PLZF mRNA levels in response to conditioning stimuli were made on CB mice at $10-12$ weeks, when background PLZF mRNA levels were low.

Luxoid (PLZF-deficient) breeding pairs from cryopreserved (B6.C3Zbtb16 ${ }^{\mathrm{LU}} / \mathrm{J}$, \# 000100) stock were obtained from The Jackson Laboratory. This mouse, first recognized in 1955 (Green, 1955), has a point mutation in the PLZF gene resulting in an attenuated protein missing the zinc finger (DNA binding) domain (Buaas et al., 2004). Progeny were genotyped by Transnetyx Inc. using a quantitative PCR (qPCR)-based system and a Zbtb16-1 MU probe able to detect the point mutation in the codon 234 that transforms an Arg codon in a nonsense codon in the luxoid mouse.

For this study we have used 86 mixed male and female B6.C3Zbtb16Lu/J 6-week-old mice,. Age- and gender-matched wild-type cage mates of the PLZF mutants, treated identically, served as controls. We also used 197 CB mice obtained from The Jackson Laboratory or from a colony established from those mice. All procedures were approved by the Institutional Animal Care and Use Committee of the Massachusetts Eye and Ear Infirmary.

Immunolocalization of PLZF. To examine the distribution of PLZF in the cochlea, mid-modiolar paraffin sections were prepared from both cochleae of $+/+$ unrestrained ( 4 mice),$+/+$ restrained ( 3 mice), and $-/-$ unrestrained (3 mice) 10- to 12-week-old B6 animals (10 mice for a total of 20 cochleae). After intracardiac perfusion with $4 \%$ paraformaldehyde in $0.1 \mathrm{~m}$ sodium phosphate buffer, $\mathrm{pH} 7.4$, cochleas were perfused with Bouin's solution (Sigma), fixed overnight, decalcified for $12 \mathrm{~h}$ in 0.5 м ETDA, dehydrated through alcohol over $24 \mathrm{~h}$, and embedded in paraffin. Sections $(10 \mu \mathrm{m})$ were dewaxed in xylene, rehydrated through alcohol into PBS, incubated overnight in 10\% goat serum, and labeled with primary antibodies to PLZF overnight [Abcam ab39354, targeting a region between amino acid 650 and the $C$ terminus of PLZF protein, dilution 1:1000; Santa Cruz Biotechnology \#SC28319 (anti-mouse PLZF d9; dilution 1:300)], placed for $1 \mathrm{~h}$ in anti mouse secondary antibody (Invitrogen Alexa Fluor 647 anti-mouse (dilution 1:500). Two different antibodies to PLZF were used to document its distribution. The images above were from the Abcam PLZF antibody, which showed very little nonspecific label. Data (data not shown) were also obtained with a Santa Cruz Biotechnology antibody, which indicated specific label [based on comparison to PLZF $(-/-)$ mice] in pillar cells and type 3 fibrocytes, but nonspecific label in the nuclei of the spiral ganglion cells.

Real-time quantitative PCR of cochlea and brain. Real-time quantitative PCR (RT-PCR) was used to assess PLZF mRNA levels in the cochlea and brain. For each sample, the spiral ganglion and organ of Corti from both ears of CB mice were pooled and dissected in RNA later (Ambion), homogenized in $1 \mathrm{ml}$ of TRIzol, and centrifuged after adding $200 \mu \mathrm{l}$ of chloroform. Supernatant $(700 \mu \mathrm{l})$ was collected and purified using RNeasy spin-columns (Qiagen). The reverse transcription reaction included: $40 \mu \mathrm{l}$ of cDNA, $11 \mu \mathrm{l}$ of $50 \mathrm{~mm} \mathrm{MgCl} 2,20 \mu \mathrm{l}$ of dNTP mix, $5 \mu \mathrm{l}$ of $2.5 \mu \mathrm{M}$ random primer (Invitrogen) and $1 \mu \mathrm{l}$ of superscript II (Invitrogen), incubated in a PTC-100 programmable thermal controller (MJ Research, Inc). Real time amplification used a Platinum qPCR super mix-UDG with ROX (Invitrogen) and a probe for mouse PLZF (Applied Biosystems, Mn001176866_m1 Zbtb16). 18S rRNA (Applied Biosystems, HS99999901-S1) was used as an internal control. Real time quantification was accomplished with one of two systems: a Stratagene MX3005P or [in earlier experiments (see Fig. $2 a$, below; supplemental Fig. 2, available at www.jneurosci.org as supplemental material)] an ABI Prism 7700 sequence Detector (PerkinElmer). Because the run and analysis algorithms of the two systems were different, we are hesitant to compare data across the two systems. Thirty-six CB embryos (mixed male and female) from 11 pregnant $\mathrm{CB}$ mice were used to analyze developmental changes in PLZF mRNA. CB mice were used for brain $(n=30)$ and cochlear $(n=36)$ expression of PLZF following restraint stress. Twenty-six CB mice were used to compare mRNA expression with restraint stress, acoustic trauma, and dexamethasone.

Western blot analysis of PLZF. To measure protein levels in the PLZF mutants, we also performed Western blot analysis of PLZF expression in $+/+,+/-$, and $-/-$ luxoid mutants (supplemental Fig. 3, available at www.jneurosci.org as supplemental material). For each sample, half of the brain from $+/+,+/-$, and $-/-$ littermates was collected and placed in $600 \mu \mathrm{l}$ of radioimmunoprecipitation buffer $(150 \mathrm{~mm} \mathrm{NaCl}, 1.0 \%$ Igepal CA-630, 0.5\% sodium deoxycholate, $0.1 \%$ SDS, $50 \mathrm{~mm}$ Tris, $\mathrm{pH} 8.0$ ) with protease inhibitor (dilution 1:100) and homogenized. After centrifugation at $15,000 \times g$ at $4^{\circ} \mathrm{C}$ for $15 \mathrm{~min}$, the supernatant was collected and boiled for $5 \mathrm{~min}$ at $100^{\circ} \mathrm{C}$. A total of $30 \mu \mathrm{l}$ of each protein sample was mixed with Laemmli sample buffer (Bio-Rad Laboratories) and loaded on a $7.5 \%$ Tris- $\mathrm{HCl}$ gel and then electrophoretically transferred to a PVDF membrane. The membrane was blocked with $10 \%$ dry milk in TBST (25 mu Tris, pH 7.5, $150 \mathrm{~mm} \mathrm{NaCl}, 0.1 \%$ Tween 20 ) for $1 \mathrm{~h}$ at room temperature. The membrane was incubated with mouse anti-PLZF (D9): sc-28319 (Santa Cruz Biotechnology; dilution 1:1000) in 1\% milk in TBST at $4^{\circ} \mathrm{C}$ overnight. After washing with TBST, the membrane was incubated with an anti-mouse HRP for $1 \mathrm{~h}$. The membrane was washed in TBST and the blots were developed by incubating the membranes with SuperSignal West Pico chemiluminescent substrate (Pierce) for $5 \mathrm{~min}$. Measurement of $\beta$ actin served as an indicant of the amount of tissue applied to each lane. To measure $\beta$ actin, the membrane was stripped for $10 \mathrm{~min}$ at room temperature with Restore Western blot stripping buffer (Thermo Scientific 21059), and incubated overnight with a mouse anti B-actin antibody (1:1000) and anti-mouse HRP (1:20.000) as described above.

Restraint stress. Restraint stress was used to induce cochlear protection from acoustic trauma. The technique is simple, reliable and can induce protection within $12 \mathrm{~h}$ (Wang and Liberman, 2002; Tahera et al., 2006b). Restraint stress was generated by restraining mice in $50 \mathrm{ml}(3$ by $11 \mathrm{~cm})$ ventilated ( $5 \mathrm{~mm}$ distributed holes) centrifuge tubes. A total of 24 B6.C3Zbtb16 ${ }^{\mathrm{Lu}} / \mathrm{J}$, aged 6 weeks $(18-25 \mathrm{~g})$, were analyzed. Each mouse was subjected to a single $12 \mathrm{~h}$ period of restraint in the ventilated tube immediately followed by a $2 \mathrm{~h}$ period of acoustic noise exposure (see below). After the exposure, animals were returned to the animal care facility for later monitoring of threshold shift. In preliminary experiments with 25 CB mice, thresholds were measured in one of the ears at $3 \mathrm{~d}, 7 \mathrm{~d}$, and $14 \mathrm{~d}$ after the noise exposure. In these animals, threshold shifts were highest at $3 \mathrm{~d}$, with lower shifts at 7 and $14 \mathrm{~d}$. Because shifts were similar at 7 and $14 \mathrm{~d}$, we chose $7 \mathrm{~d}$ after the exposure to assess threshold shift in auditory brainstem response (ABR) and distortion product otoacoustic emissions (DPOAEs).

Acoustic overexposures. Acoustic overexposures were used to generate cochlear damage. The acoustic stimulus was an octave band of noise $(8-16 \mathrm{kHz})$ delivered at $100 \mathrm{~dB}$ SPL, for $2 \mathrm{~h}$. Exposures were delivered to awake mice restrained within small cells in a subdivided cage (1 animal/ cell). The cage was placed directly below the horn of the sound-delivery loudspeaker in rotating platform in a small, reverberant chamber. Noise calibration to target the sound pressure level was performed immediately before each exposure session. Sound pressure levels varied by $<1 \mathrm{~dB}$ across the cells. In a small subset of experiments, mice were exposed to either 88 or $102 \mathrm{~dB}$ SPL for $2 \mathrm{~h}$ to determine the effects of higher-level acoustic overexposure on PLZF levels.

Dexamethasone administration. Dexamethasone sodium phosphate (American Regent, Inc) at $4 \mathrm{mg} / \mathrm{ml}$ was diluted to $0.25 \mathrm{mg} / \mathrm{ml}$ with saline, and delivered intraperitoneally at doses of $0.005,0.05,0.15,0.5,1.5$, and $5 \mathrm{mg} / \mathrm{kg}$. Intraperitoneal administration of $0.5 \mathrm{ml}$ of saline served as a control. Each dose was administered to three to seven 12-week-old CB mice (total $=46$ mice). Dexamethasone was delivered either immediately before or immediately after the acoustic overexposure (see above). DPOAE and ABR thresholds were measured $7 \mathrm{~d}$ later. In $4 \mathrm{CB}$ mice, 0.5 $\mathrm{mg} / \mathrm{kg}$ dexamethasone was administered and the mice killed $3 \mathrm{~h}$ later for analysis of PLZF mRNA levels.

Physiological tests. Mice were anesthetized with ketamine $(100 \mathrm{mg} / \mathrm{kg}$, i.p.) and xylazine $(10 \mathrm{mg} / \mathrm{kg}$, i.p.). Acoustic stimuli $(5.6-45 \mathrm{kHz})$ were delivered via a custom acoustic assembly consisting of two electrostatic drivers as sound sources (EC-1, Tucker Davis Technologies) and a miniature electret microphone to measure sound pressure in situ. ABRs were recorded via subdermal needle electrodes (vertex-ventrolateral to the pinna of the test ear with a ground at the base of the tail). The response from the electrodes was amplified $(10,000 \mathrm{x})$, filtered $(0.1-3 \mathrm{kHz}$ bandpass), and averaged (512 samples at each frequency-level combination). 


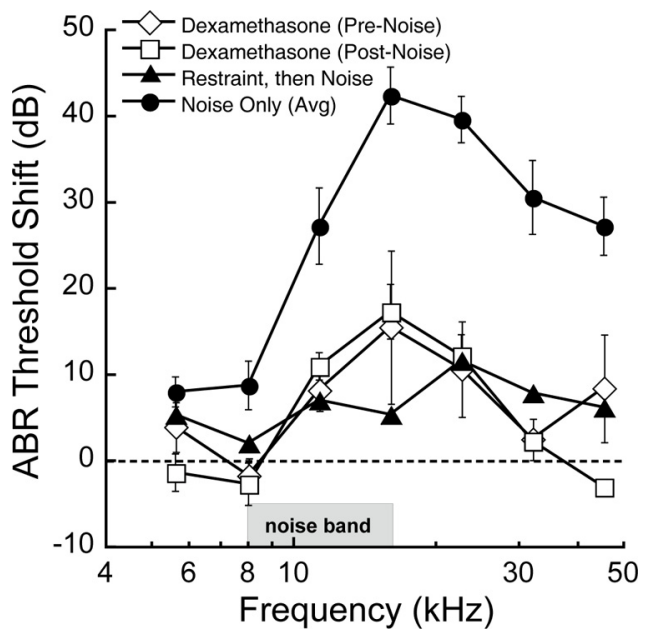

Figure 1. Exposure of mice to $2 \mathrm{~h}$ noise $(8-16 \mathrm{kHz}, 100 \mathrm{~dB} S P L)$ induced $30-40 \mathrm{~dB}$ of permanent threshold shift measured $7 \mathrm{~d}$ after the exposure (filled circles). Plotted are means \pm SE. The amount of threshold shift was reduced when the noise was preceded by a $12 \mathrm{~h}$ period of restraint stress (filled triangles; $p<0.001$ by ANOVA) or when the mice were given dexamethasone $(0.5 \mathrm{mg} / \mathrm{kg}$, i.p.) either immediately before (open diamonds; $p<0.005$ by ANOVA) or after (open squares; $p<0.001$ by ANOVA) the noise exposure. Restraint stress was performed on 6-week-old B6 mice, the background strain for the luxoid mutant (see Fig. 4). Dexamethasone experiments were performed on 10- to 12-week-old CB mice. Threshold shifts were obtained by subtracting thresholds following noise exposure from those of unexposed animals. Noise-only shifts for 6 week B6 and 10-12 week CB were similar and were combined here for display purposes. Individual plots for dexamethasone effects in $C B$ mice and restraint stress effects in B6 mice are presented as supplemental Figure 1 (available at www.jneurosci.org as supplemental material).
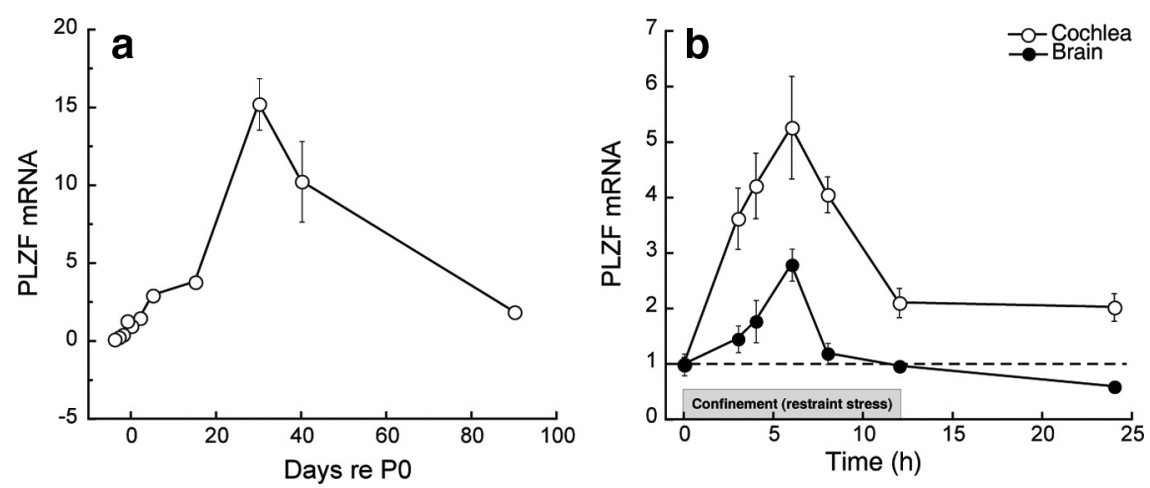

Figure 2. PLZF mRNA levels during development and in restraint-stressed adults. $\boldsymbol{a}$, Quantitative RT-PCR of cochleae (organ of Corti and spiral ganglia) indicated that PLZF mRNA levels increased until P30, and declined rapidly thereafter. $\boldsymbol{b}$, Restraint stress increased cochlear PLZF mRNA in the adult (P90). Levels increased during the period of restraint (shaded bar), peaking at $8 \mathrm{~h}$ ( $p<$ 0.0001 when compared with time 0 by unpaired Student's $t$ test) and returned toward normal even during continued restraint. The time course of PLZF changes in the brain were similar to those in the cochlea $(p<0.001$ at $6 \mathrm{~h}$ ). Plotted are means \pm SE. Each point in $\boldsymbol{a}$ represents data from 3-4 mice. Each point in $\boldsymbol{b}$ represents four to six 10 - to 12-week-old CB mice, except for time point 0 (8 mice).

Sound level was incremented in $5 \mathrm{~dB}$ steps, from $\sim 10 \mathrm{~dB}$ below threshold to $90 \mathrm{~dB}$ SPL. Threshold for ABR was defined as the lowest stimulus level at which a repeatable wave could be identified in the response waveform. DPOAEs were recorded for primary tones $(\mathrm{f} 1, \mathrm{f} 2)$ over the same $\mathrm{f} 2$ range of frequencies, with a frequency ratio of 1.2 , and with the level of the $\mathrm{f} 2$ primary $10 \mathrm{~dB}$ less than $\mathrm{f} 1$ level. Primaries were incremented together in $5 \mathrm{~dB}$ steps from $\sim 10 \mathrm{~dB}$ below threshold to $80 \mathrm{~dB}$ SPL. Ear-canal sound pressure was amplified and digitally sampled, fast Fourier transforms were computed and averaged, and the 2f1-f2 DPOAE and surrounding noise floor were extracted. Iso-response contours were interpolated from plots of response amplitude vs sound level. "Threshold" is defined as the f1 level required to produce a DPOAE of $-5 \mathrm{~dB}$ SPL. In each animal, we looked only at the response from the right ear. Threshold contours were compared and statistically analyzed with a two-way ANOVA.

\section{Results}

Both restraint stress and corticosteroids can induce protection from acoustic trauma

We used restraint stress to induce cochlear protection from acoustic trauma. To measure protection, we exposed mice to a $2 \mathrm{~h}$ period of $100 \mathrm{~dB}$ SPL $(8-16 \mathrm{kHz})$ noise in the presence and absence of restraint stress (Fig. 1). Noise alone induced threshold elevations, measured $7 \mathrm{~d}$ later, of $\sim 30-40 \mathrm{~dB}$, indicating permanent threshold shift. When restraint stress was administered immediately before this same noise exposure, hearing loss was much smaller; generally $<10 \mathrm{~dB}$ of threshold shift was observed.

We compared the protective effects of restraint stress to those of the corticosteroid, dexamethasone $(0.5 \mathrm{mg} / \mathrm{kg}$, i.p. $)$, administered either immediately before or after noise exposure (Fig. 1). Dexamethasone provided an amount of protection similar to restraint stress. Importantly, the amount of protection was the same whether the dexamethasone was administered before or after the trauma, indicating that the protective mechanism does not involve an attenuation of the physical input to the inner ear. The effects of dexamethasone were sharply dependent on dose: 0.5 and $1.5 \mathrm{mg} / \mathrm{kg}$ produced protection similar as that illustrated in Figure $1(\sim 30 \mathrm{~dB}$ at 16 and $22 \mathrm{kHz})$, but the effects at 0.15 or $5 \mathrm{mg} / \mathrm{kg}$ were similar to those with saline, which afforded a small amount $(\sim 15 \mathrm{~dB})$ protection, possibly due to stress of the intraperitoneal injection itself.

\section{Restraint stress, corticosteroids, and acoustic stimulation reversibly increased PLZF mRNA levels}

We determined whether restraint stress or dexamethasone could induce production of PLZF by measuring PLZF mRNA using quantitative, real-time PCR. We first analyzed levels of PLZF mRNA as a function of mouse age (Fig. 2a). This indicated endogenous cochlear levels were highest around postnatal day 30 (P30) and dropped considerably by $\mathrm{P} 90$. We used P90 mice for subsequent analyses to take advantage of their lower background levels of PLZF. Restraint stress reversibly increased PLZF mRNA in both the cochlea and the brain (Fig. 2b), with peak levels observed between 4 and 8 h of restraint. Dexamethasone $(0.5 \mathrm{mg} / \mathrm{kg}$, i.p. $)$ elevated cochlear PLZF mRNA around fivefold $(4.84 \pm 0.83$; mean \pm SE; $n=4$ mice; $p=$ 0.018 by Student's unpaired $t$ test), measured $3 \mathrm{~h}$ after a single injection (data not shown).

We also evaluated changes in PLZF mRNA following acoustic overexposure. Mice were confined in the exposure chamber and exposed to $2 \mathrm{~h}$ of $8-16 \mathrm{kHz}$ noise at 88 or $102 \mathrm{~dB}$ SPL, or were simply confined to the chamber for $2 \mathrm{~h}$. PLZF mRNA was measured $2 \mathrm{~h}$ after the exposure (supplemental Fig. 2, available at www.jneurosci. org as supplemental material). Acoustic overexposure produced elevations in PLZF. However, simply confining the animal in the exposure chamber also-evoked elevations in PLZF mRNA. 


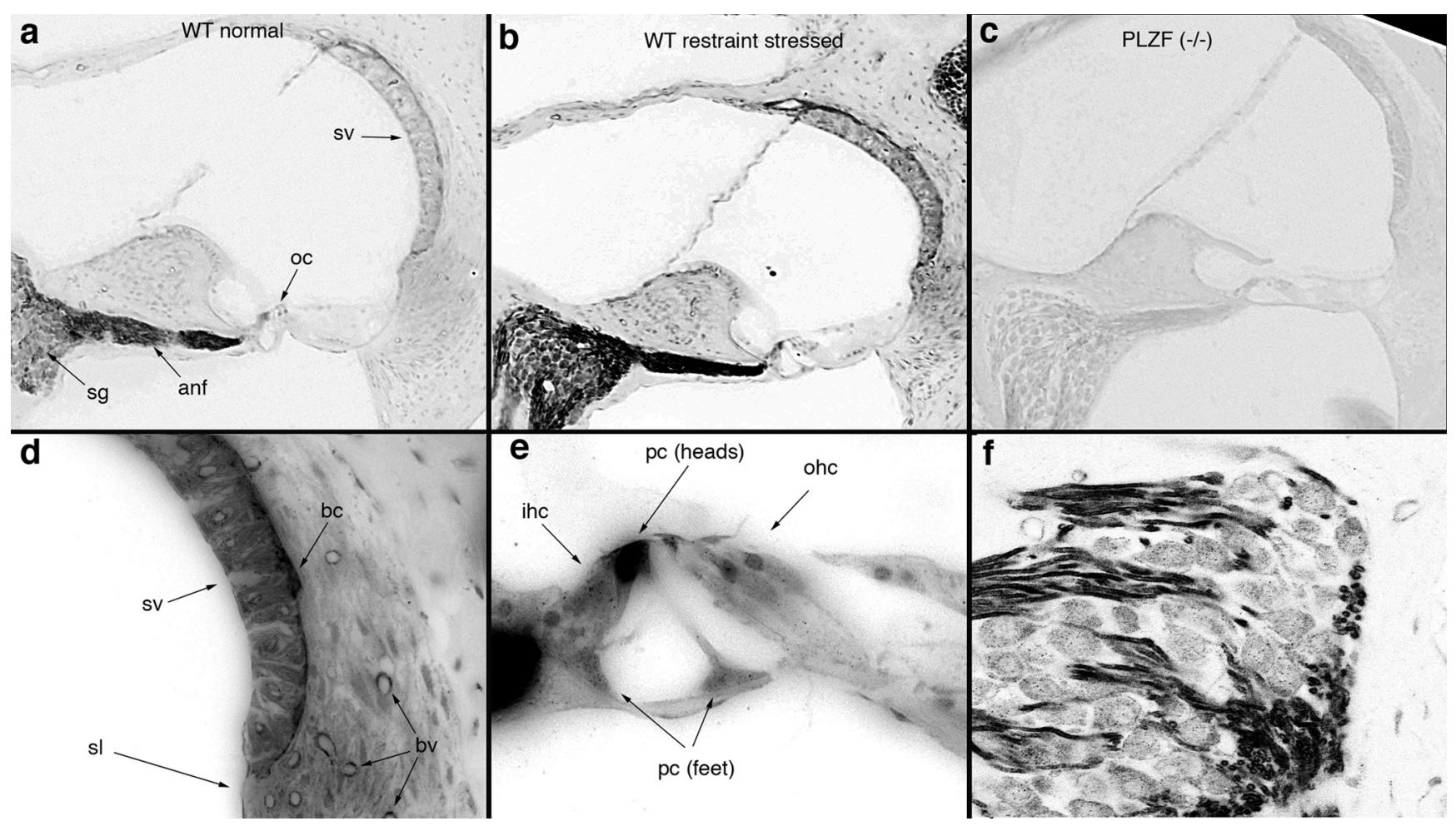

Figure 3. Intense PLZF immunoreactivity is observed in the auditory nerve, organ of Corti, and stria vascularis. $\boldsymbol{a}-\boldsymbol{c}$, PLZF immunoreactivity from mice at rest (a) or following exposure to $12 \mathrm{~h}$ of restraint stress $(\boldsymbol{b})$ showed similar patterns of labeling, though labeling was more intense following restraint stress. No labeling in the luxoid [PLZF (-/-)] mouse (c) indicates specificity of the antibody. Sections in $\boldsymbol{a}-\boldsymbol{c}$ were immunoreacted together and images were taken at identical exposure levels. $\boldsymbol{d}$ - $\boldsymbol{f}$, Higher-power images of the lateral wall (d), organ of Corti (e), and spiral ganglion $(\boldsymbol{f})$ are presented. Strongest label is observed in the auditory nerve, in heads of the pillar cells ( $\mathrm{pc}$ ), and in basal cells (bc) of the stria vascularis (sv), but label is widely distributed throughout the cochlea, including: sv, fibrocytes of the spiral ligament (sl), and blood vessels (bv); the phalangeal processes of Dieter's cells, inner hair cells (ihc), and outer hair cells (ohc) of the organ of (orti (oc) (see also Nagy et al., 2005); and neuronal cell bodies of the spiral ganglion neuron, where punctate label in the cytoplasm is evident. Observations were made on both cochleae from 6 wild-type and 4 homozygous mutant mice.

\section{PLZF immunolabel is present in the cochlea}

We determined the cellular distribution of PLZF using immunohistochemistry in the adult cochlea. PLZF immunoreactivity (Fig. 3) was highest in the cochlear nerve, the pillar cells of the organ of Corti, and in basal cells of the stria vascularis, but was widely distributed throughout the cochlea (Fig. 3a,b). Homozygous mutant controls (PLZF - /-) mice-see below) showed no immunolabel with PLZF antibody (Fig. 3c). PLZF label in the auditory nerve (Fig. $3 f$ ) appeared primarily in the Schwann cells: label terminated centrally at the Schwann cell-glial cell (CNS) border and terminated peripherally at the habenula perforata, where the auditory neurons become unmyelinated. Neuronal cell bodies were also labeled, though not as strongly. The stria vascularis was more strongly labeled than the surrounding tissue, and within the stria, labeling was strongest in the basal cells (Fig. $3 d$ ). Within the organ of Corti (Fig. 3e), label was often very strong in the heads and feet of the pillar cells, but was also present in the hair cells and supporting (Deiter's) cells (see also Nagy et al., 2005). To determine whether restraint stress altered PLZF distribution, we exposed mice to restraint stress and immunolabeled the cochlea with antibodies to PLZF. Immunoreactivity was increased and generally distributed among the same cells expressing PLZF in the absence of restraint stress (compare Fig. 3a,b).

We examined the auditory phenotype of PLZF-deficient mice To determine whether the increases we observed in PLZF following restraint stress were essential to induce protection, we established a breeding colony from cryopreserved luxoid mice obtained from The Jackson Laboratory. This mouse has a point mutation in the PLZF gene resulting in an attenuated protein missing the zinc finger (DNA binding) domain (Buaas et al., 2004). PLZF-deficient homozygotes (-/-) exhibit polydactyly, mild hindlimb abnormalities, fusion of vertebrae, and spermatogonia dysfunction (Green, 1955; Barna et al., 2000; Buaas et al., 2004; Ching et al., 2010). The auditory phenotype of this mouse has not been previously described, so we describe it here. We observed no gross histological defects in the cochlea. We studied cochlear function across a broad range of frequencies (5.6-45 $\mathrm{kHz}$ ) using two physiological measures: (1) DPOAEs, which reflect cochlear outer hair cell function and (2) ABRs, which represent the summed activity of the auditory nerve. In 4-week-old $-/-$ mice, ABR and DPOAE thresholds to acoustic stimulation were slightly poorer $(\sim 10 \mathrm{~dB})$ than those of wild-type mice (data not shown). Heterozygotes $(+/-)$ of the same age had normal $\mathrm{ABR}$ and DPOAE responses. By 6 weeks, $-/-$ mice had ABR and DPOAE threshold elevations of 15-30 dB (Fig. 4) and prolonged $(0.2 \mathrm{~ms})$ wave 1 latencies relative to wild types, while $+/-$ mice maintained nearly normal responses.

\section{PLZF-deficient mice cannot induce protection from acoustic trauma with restraint stress}

Since elevations of baseline threshold can reduce noise-induced threshold shift, to assess the role of PLZF in conditioning we studied PLZF heterozygotes, with nearly normal baseline thresholds but only half the normal protein (supplemental Fig 3, available at www.jneurosci.org as supplemental material). Unconditioned (no restraint stress) PLZF $(+/-)$ mice and their wild-type littermates showed similar vulnerability to acoustic 
$\mathrm{ABR}$
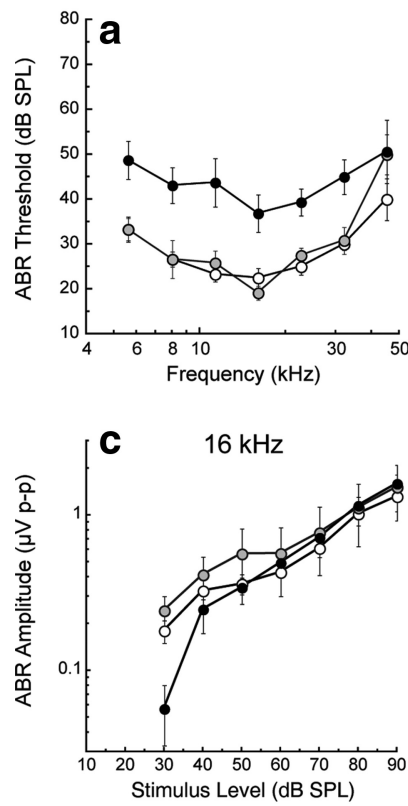

DPOAE
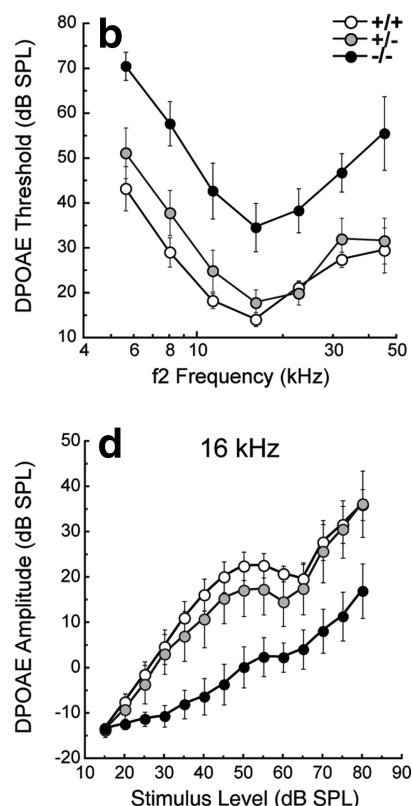

Figure 4. Baseline thresholds and suprathreshold ABRs and DPOAEs in PLZF mutants versus wild types. $\boldsymbol{a}, \boldsymbol{b}$, Thresholds for unexposed groups of animals [PLZF-deficient homozygotes $(-/-)$ and heterozygotes $(+/-)$, and wild types, 6 weeks of age $]$ are shown for $A B R s(a)$ and DPOAEs $(\boldsymbol{b}) . \boldsymbol{c}, \boldsymbol{d}$, Response growth with increasing stimulus level is shown, for example, at 16 $\mathrm{kHz}$ in $\mathbf{c}(\mathrm{ABR})$ and $\boldsymbol{d}$ (DPOAE). PLZF-deficient - / - mice demonstrate ABR and DPOAE threshold elevations of $15-30 \mathrm{~dB}$ and reduced suprathreshold amplitudes relative to $+1+(p<$ 0.01 by ANOVA), while $+1-$ mice maintained nearly normal responses ( $p>0.05$ by ANOVA). Data are expressed as means \pm SE, with $4-8$ mice in each group. The key in $\boldsymbol{b}$ applies to all panels.

overexposure at the frequency regions of maximum shift $(30-40$ $\mathrm{dB}$ ). Shifts persisted for both groups at $15 \mathrm{~d}$ postexposure (data not shown) indicating permanent threshold shifts. Restraint stress, applied immediately before acoustic overstimulation, provided nearly complete protection in wild-types (Fig. $5 a, c)$ : ABR thresholds $7 \mathrm{~d}$ after exposure were elevated only $5-10 \mathrm{~dB}$. This protective effect was also seen in DPOAE thresholds (Fig. $5 c$ ). In contrast, in PLZF-deficient $(+/-)$ mice, restraint stress failed to provide protection from overexposure (Fig. 5b,d): threshold shifts were as large as in the un-conditioned group.

\section{Discussion}

Our findings indicate that PLZF, a corticosteroid-responsive transcription protein, is a strong candidate to mediate conditioning-induced protection of the cochlea from acoustic trauma. The central finding supporting this hypothesis is that mice deficient in PLZF are unable to generate protection with restraint stress. Additional support comes from our observation that PLZF mRNA levels are increased in the cochlea following stimuli that induce conditioning, including restraint stress, dexamethasone, and acoustic overexposure. Finally, PLZF immunoreactivity is present in the cochlea including the spiral ganglion, the lateral wall, and, as previously noted (Nagy et al., 2005), the organ of Corti, all targets for acoustic trauma (Wang et al., 2002). Our observation that dexamethasone induced similar amounts of protection whether administered before or after the acoustic trauma suggests that the protective effects associated with PLZF are not simply due to attenuating the mechanical stimulus to the organ of Corti, but may involve either attenuation of a damage process that occurs following the stimulus, repair of damage suf-
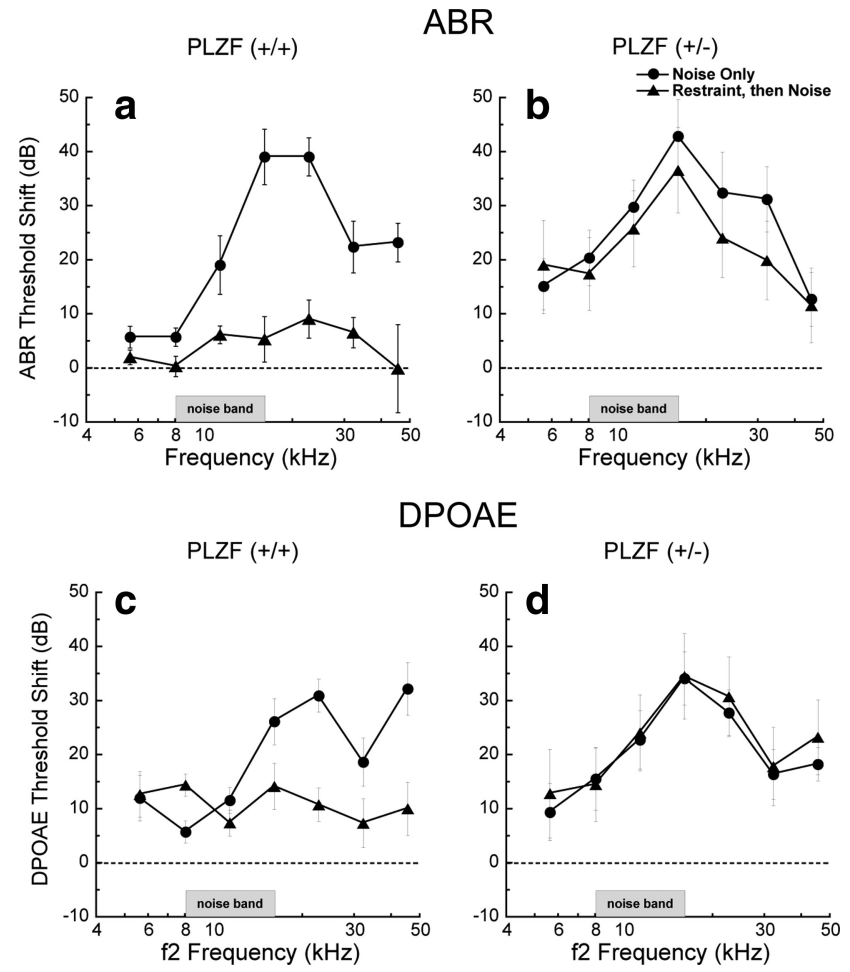

Figure 5. PLZF-deficient mice cannot induce protection from acoustic trauma with restraint stress. Plotted are ABR thresholds as a function of frequency for wild-type mice (PLZF $(+/+)$; left) and PLZF-deficient (+/-) mice (right) measured $7 \mathrm{~d}$ after a $2 \mathrm{~h}$ exposure to a $100 \mathrm{dBSPL}$ broadband $(8-16 \mathrm{kHz})$ sound. In wild-type mice, restraint stress administered just before the noise exposure prevented most of the noise-induced hearing loss ( $p<0.001$ by ANOVA), while PLZF-deficient mice were not able to generate protection with restraint stress ( $p>0.05$ by ANOVA). Means \pm SE with 4-7 mice in each group.

fered during the acoustic trauma, or both. This opens the possibility that the protective pathways induced by PLZF may be generalizable to understanding other therapeutic actions of corticosteroids.

\section{Organisms have developed several means of protecting the cochlea from acoustic overstimulation}

Middle ear muscle contraction and activation of olivocochlear efferent pathways effectively attenuate the stimulus presented to the organ of Corti with a time course measured in ms. Conditioning-induced protection is interesting because it appears to involve some "metabolic" process requiring hours to develop. The phenomenon of conditioning originally referred to protection induced by preexposure to moderate-level (nontraumatic) sound (Canlon et al., 1988; Campo et al., 1991; Ryan et al., 1994; Niu and Canlon, 2002), but a variety of stimuli have been found to induce conditioning, including restraint stress (Wang and Liberman, 2002; Tahera et al., 2006b), heat stress (Yoshida et al., 1999), sham surgery (Kujawa and Liberman, 1997), corticosteroids (Takemura et al., 2004; Tabuchi et al., 2006; Tahera et al., 2006b), kanamycin (Fernandez et al., 2010), and hypoxia (Gagnon et al., 2007). Indeed, Wang and Liberman (2002) suggested that it is the stress that results from exposure to the acoustic conditioning procedure, rather than the acoustic signal itself, that may underlie the protection. This suggestion is supported by our observation that simply restraining the animal in the acoustic exposure chamber produced increases in PLZF mRNA similar to those in response to a moderate level ( $88 \mathrm{~dB}$ SPL) sound classically used to evoke conditioning (Yoshida and Liberman, 2000). 
Our observation that cochlear PLZF mRNA levels are increased by exposure to moderate- to high-level acoustic stimulation suggests that this putative protective mechanism is evoked during traumatic acoustic exposure, though the amount of protection evoked may be small based on our observation that wildtype and PLZF $(+/-)$ mice respond similarly to acoustic overexposure at the frequencies of maximum threshold shift. There is obviously additional protection associated with prior exposure to restraint stress or concomitant exposure to dexamethasone (Figs. 1, 5). As yet unexplored are a number of factors in the relation between PLZF elevation and protection. For example, questions such as how long must PLZF be elevated and what is the relationship between PLZF elevation and the time of optimal protection are not answered. In addition, the possibility that other factors also play a role in generating protection must be considered. Our work demonstrates that PLZF is necessary to generate protection by restraint stress, but does not show whether or not is sufficient.

\section{Glucocorticoid receptor activation may mediate several forms of protection from acoustic overexposure}

Restraint stress evokes corticosteroid release from the adrenal gland (Curtis and Rarey, 1995) and Canlon and colleagues (Tahera et al., 2006b) present evidence that restraint stress provides protection via a corticosteroid mediator. Corticosteroid release is evoked by other conditioning stimuli such as hypoxia (Raff et al., 1983) and heat stress (Djordjević et al., 2003). Synthetic corticosteroids such as methylprednisolone (Takahashi et al., 1996) and dexamethasone (Takemura et al., 2004; Tahera et al., 2006a) can induce protection from threshold shift associated with high level sound. PLZF production is increased in response to corticosteroids, but is also increased in response to a variety of other stimuli, including aldosterone, progesterone and androgens (Jiang and Wang, 2004; Náray-Fejes-Tóth et al., 2008). Thus it plausible non-corticosteroidal mechanisms may also be at play in evoking PLZF-induced protection.

\section{Mechanisms of PLZF-induced protection}

While activation of corticosteroid receptors often results in DNA binding of the receptor-ligand complex and subsequent alteration in gene expression (Giguère et al., 1986), a non-genomic action of corticosteroids on PLZF expression has been implicated in an analysis of endometrial stromal cells (Fahnenstich et al., 2003). The cytosolic localization of PLZF both in the control and restrained mice suggests it may be binding and recruiting cytosolic protein targets to the nucleus, as has been demonstrated for its interaction with epsin (Hyman et al., 2000) and with the G-protein coupled angiotensin II receptor (Senbonmatsu et al., 2003). In that regard, PLZF has been shown to be an interaction partner with prestin (Nagy et al., 2005), the major protein functioning as the cochlear amplifier in the outer hair cell (Zheng et al., 2000). Both espin and prestin appear to bind to the same region of PLZF (at the first of nine zinc finger domains near the $\mathrm{C}$ terminus), leading Nagy et al. (2005) to suggest a similar interaction between PLZF and prestin.

The acoustic exposure we used ( $100 \mathrm{~dB}$ SPL, $8-16 \mathrm{kHz}$ for $2 \mathrm{~h}$ ) was identical to that used by Wang et al. (2002) to correlate histological changes to physiological changes in 10-week-old CB mice. Their conclusion was that the PTS correlated to stereociliary damage when the sound exposure was lower than that which produced frank rupture of the reticular lamina. For the exposure we used, the most likely correlate would be damage to the outer hair cell stereocilia.
Maintenance of cochlear stereocilia appears to be a very dynamic process with association and disassociation of actin filaments under active control (Rzadzinska et al., 2004; Belyantseva et al., 2009; Peng et al., 2009; Herde et al., 2010; Zheng et al., 2010). Stereocilia damage becomes more severe with increasing time or intensity of acoustic exposure, a finding that might be interpreted as an inability of these dynamic processes to keep up with an increased demand associated with acoustic overstimulation. Dexamethasone provided protection from PTS in similar amounts whether given before or after the acoustic overexposure, implying that protection is not attenuating the stimulus input in any way, but involves either attenuation of a damage process that occurs following the stimulus or repair of damage suffered during the acoustic trauma (or both).

Corticosteroids are, at present, one of the few available treatments for acute loss of hearing, and their mechanisms of action are not understood (Rauch et al., 2000; Schreiber et al., 2010). While many promising potential targets of steroid activation have been analyzed in the ear (Tahera et al., 2006a; Haake et al., 2009), no compelling mechanism has yet been identified for its action. We raise the possibility that PLZF elevation represents one component, of the broad spectrum of corticosteroid actions, which may be responsible for cochlear protection. The spectrum of damage produced in acoustic trauma overlaps the spectrum of loss with other forms of degenerative sensorineural hearing loss, ranging from strial and ligament pathology to hair cell and spiral ganglion neuron loss (Wang and Liberman, 2002). It is possible that protective mechanisms in acoustic trauma are shared with those for other modes of cochlear injury and degeneration.

\section{It is plausible that PLZF is responsible for protective effects of corticosteroids in the brain and spinal cord}

PLZF is present in the brain and is elevated following restraint stress with a similar time course to the changes we observe in the cochlea (Fig. 2). Corticosteroids have some beneficial therapeutic actions in brain and spinal cord trauma, though the complex array of actions associated with these agents limit their clinical usefulness (Roberts et al., 2004). Our identification of a single, corticosteroid-responsive transcription factor that is essential to induce conditioning-mediated protection from acoustic trauma offers a straightforward opportunity to identify specific molecular mechanisms that protect and repair the cochlea. One can speculate that there is a steroid-responsive molecular pathway involved in protection and prevention of cochlear degeneration following acoustic trauma that may prove useful in treating other forms of hearing loss or brain injury.

\section{References}

Barna M, Hawe N, Niswander L, Pandolfi PP (2000) Plzf regulates limb and axial skeletal patterning. Nat Genet 25:166-172.

Belyantseva IA, Perrin BJ, Sonnemann KJ, Zhu M, Stepanyan R, McGee J, Frolenkov GI, Walsh EJ, Friderici KH, Friedman TB, Ervasti JM (2009) Gamma-actin is required for cytoskeletal maintenance but not development. Proc Natl Acad Sci U S A 106:9703-9708.

Buaas FW, Kirsh AL, Sharma M, McLean DJ, Morris JL, Griswold MD, de Rooij DG, Braun RE (2004) Plzf is required in adult male germ cells for stem cell self-renewal. Nat Genet 36:647-652.

Campo P, Subramaniam M, Henderson D (1991) The effect of 'conditioning' exposures on hearing loss from traumatic exposure. Hear Res 55:195-200.

Canlon B, Borg E, Flock A (1988) Protection against noise trauma by preexposure to a low level acoustic stimulus. Hear Res 34:197-200.

Ching YH, Wilson LA, Schimenti JC (2010) An allele separating skeletal patterning and spermatogonial renewal functions of PLZF. BMC Dev Biol 10:33. 
Curtis LM, Rarey KE (1995) Effect of stress on cochlear glucocorticoid protein. II. Restraint. Hear Res 92:120-125.

Djordjević J, Cvijić G, Davidović V (2003) Different activation of ACTH and corticosterone release in response to various stressors in rats. Physiol Res 52:67-72.

Fahnenstich J, Nandy A, Milde-Langosch K, Schneider-Merck T, Walther N, Gellersen B (2003) Promyelocytic leukaemia zinc finger protein (PLZF) is a glucocorticoid- and progesterone-induced transcription factor in human endometrial stromal cells and myometrial smooth muscle cells. Mol Hum Reprod 9:611-623.

Fernandez EA, Ohlemiller KK, Gagnon PM, Clark WW (2010) Protection against noise-induced hearing loss in young CBA/J mice by low-dose kanamycin. J Assoc Res Otolaryngol 11:235-244.

Gagnon PM, Simmons DD, Bao J, Lei D, Ortmann AJ, Ohlemiller KK (2007) Temporal and genetic influences on protection against noise-induced hearing loss by hypoxic preconditioning in mice. Hear Res 226:79-91.

Giguère V, Hollenberg SM, Rosenfeld MG, Evans RM (1986) Functional domains of the human glucocorticoid receptor. Cell 46:645-652.

Green M (1955) A new hereditary leg and foot abnormality in the house mouse. J Hered 46:91-99.

Haake SM, Dinh CT, Chen S, Eshraghi AA, Van De Water TR (2009) Dexamethasone protects auditory hair cells against TNFalpha-initiated apoptosis via activation of PI3K/Akt and NFkappaB signaling. Hear Res 255:22-32.

Herde MK, Friauf E, Rust MB (2010) Developmental expression of the actin depolymerizing factor $\mathrm{ADF}$ in the mouse inner ear and spiral ganglia. J Comp Neurol 518:1724-1741.

Hyman J, Chen H, Di Fiore PP, De Camilli P, Brunger AT (2000) Epsin 1 undergoes nucleocytosolic shuttling and its eps15 interactor $\mathrm{NH}(2)$ terminal homology (ENTH) domain, structurally similar to Armadillo and HEAT repeats, interacts with the transcription factor promyelocytic leukemia Zn(2) + finger protein (PLZF). J Cell Biol 149:537-546.

Jiang F, Wang Z (2004) Identification and characterization of PLZF as a prostatic androgen-responsive gene. Prostate 59:426-435.

Kujawa SG, Liberman MC (1997) Conditioning-related protection from acoustic injury: effects of chronic deefferentation and sham surgery. J Neurophysiol 78:3095-3106.

Li HS (1992) Influence of genotype and age on acute acoustic trauma and recovery in CBA/Ca and C57BL/6J mice. Acta Otolaryngol 112:956-967.

Miller JD, Watson CS, Covell WP (1963) Deafening effects of noise on the cat. Acta Otolaryngol Suppl 176:1-91.

Nagy I, Bodmer M, Schmid S, Bodmer D (2005) Promyelocytic leukemia zinc finger protein localizes to the cochlear outer hair cells and interacts with prestin, the outer hair cell motor protein. Hear Res 204:216-222.

Náray-Fejes-Tóth A, Boyd C, Fejes-Tóth G (2008) Regulation of epithelial sodium transport by promyelocytic leukemia zinc finger protein. Am J Physiol Renal Physiol 295:F18-F26.

Niu X, Canlon B (2002) Protective mechanisms of sound conditioning. Adv Otorhinolaryngol 59:96-105

Ohlemiller KK, Wright JS, Heidbreder AF (2000) Vulnerability to noiseinduced hearing loss in 'middle-aged' and young adult mice: a doseresponse approach in CBA, C57BL, and BALB inbred strains. Hear Res 149:239-247.

Peng AW, Belyantseva IA, Hsu PD, Friedman TB, Heller S (2009) Twinfilin 2 regulates actin filament lengths in cochlear stereocilia. J Neurosci 29:15083-15088.

Raff H, Shinsako J, Keil LC, Dallman MF (1983) Vasopressin, ACTH, and corticosteroids during hypercapnia and graded hypoxia in dogs. Am J Physiol 244:E453-E458.

Rauch F, Travers R, Norman ME, Taylor A, Parfitt AM, Glorieux FH (2000) Deficient bone formation in idiopathic juvenile osteoporosis: a histomorphometric study of cancellous iliac bone. J Bone Miner Res 15:957-963.

Roberts I, Yates D, Sandercock P, Farrell B, Wasserberg J, Lomas G, Cottingham R, Svoboda P, Brayley N, Mazairac G, Laloë V, Muñoz-Sánchez A, Arango M, Hartzenberg B, Khamis H, Yutthakasemsunt S, Komolafe E, Olldashi F, Yadav Y, Murillo-Cabezas F, et al. (2004) Effect of intravenous corticosteroids on death within 14 days in 10008 adults with clinically significant head injury (MRC CRASH trial): randomised placebo-controlled trial. Lancet 364:1321-1328.

Ryan AF, Bennett TM, Woolf NK, Axelsson A (1994) Protection from noise-induced hearing loss by prior exposure to a nontraumatic stimulus: role of the middle ear muscles. Hear Res 72:23-28.

Rzadzinska AK, Schneider ME, Davies C, Riordan GP, Kachar B (2004) An actin molecular treadmill and myosins maintain stereocilia functional architecture and self-renewal. J Cell Biol 164:887-897.

Schreiber BE, Agrup C, Haskard DO, Luxon LM (2010) Sudden sensorineural hearing loss. Lancet 375:1203-1211.

Senbonmatsu T, Saito T, Landon EJ, Watanabe O, Price E Jr, Roberts RL, Imboden H, Fitzgerald TG, Gaffney FA, Inagami T (2003) A novel angiotensin II type 2 receptor signaling pathway: possible role in cardiac hypertrophy. EMBO J 22:6471-6482.

Tabuchi K, Murashita H, Sakai S, Hoshino T, Uemaetomari I, Hara A (2006) Therapeutic time window of methylprednisolone in acoustic injury. Otol Neurotol 27:1176-1179.

Tahera Y, Meltser I, Johansson P, Bian Z, Stierna P, Hansson AC, Canlon B (2006a) NF-kappaB mediated glucocorticoid response in the inner ear after acoustic trauma. J Neurosci Res 83:1066-1076.

Tahera Y, Meltser I, Johansson P, Hansson AC, Canlon B (2006b) Glucocorticoid receptor and nuclear factor-kappa B interactions in restraint stress-mediated protection against acoustic trauma. Endocrinology 147:4430-4437.

Takahashi K, Kusakari J, Kimura S, Wada T, Hara A (1996) The effect of methylprednisolone on acoustic trauma. Acta Otolaryngol 116:209-212.

Takemura K, Komeda M, Yagi M, Himeno C, Izumikawa M, Doi T, Kuriyama H, Miller JM, Yamashita T (2004) Direct inner ear infusion of dexamethasone attenuates noise-induced trauma in guinea pig. Hear Res 196:58-68.

Wang Y, Liberman MC (2002) Restraint stress and protection from acoustic injury in mice. Hear Res 165:96-102.

Wang Y, Hirose K, Liberman MC (2002) Dynamics of noise-induced cellular injury and repair in the mouse cochlea. J Assoc Res Otolaryngol 3:248-268.

Wasim M, Carlet M, Mansha M, Greil R, Ploner C, Trockenbacher A, Rainer J, Kofler R (2010) PLZF/ZBTB16, a glucocorticoid response gene in acute lymphoblastic leukemia, interferes with glucocorticoid-induced apoptosis. J Steroid Biochem Mol Biol 120:218-227.

Yoshida N, Liberman MC (2000) Sound conditioning reduces noiseinduced permanent threshold shift in mice. Hear Res 148:213-219.

Yoshida N, Kristiansen A, Liberman MC (1999) Heat stress and protection from permanent acoustic injury in mice. J Neurosci 19:10116-10124.

Zheng J, Shen W, He DZ, Long KB, Madison LD, Dallos P (2000) Prestin is the motor protein of cochlear outer hair cells. Nature 405:149-155.

Zheng L, Zheng J, Whitlon DS, García-Añoveros J, Bartles JR (2010) Targeting of the hair cell proteins cadherin 23, harmonin, myosin XVa, espin, and prestin in an epithelial cell model. J Neurosci 30:7187-7201. 